\title{
Conflict or Coordination? Assessment of Coordinated Development between Socioeconomic and Ecological Environment in Resource-based Cities $₫$ Evidence from Sichuan Province of China
}

\author{
Yi Xiao \\ Chengdu University of Technology \\ Yuan Li \\ Sichuan University \\ Huan Huang ( $\sim$ Benbenyi93@163.com ) \\ Chengdu University of Technology
}

\section{Research Article}

Keywords: Socioeconomic, Ecological environment, Resource-based cities, Sichuan province, Coupling coordination degree

Posted Date: May 13th, 2021

DOI: https://doi.org/10.21203/rs.3.rs-429436/v1

License: (c) (1) This work is licensed under a Creative Commons Attribution 4.0 International License. Read Full License

Version of Record: A version of this preprint was published at Environmental Science and Pollution Research on July 31st, 2021. See the published version at https://doi.org/10.1007/s11356-021-15740-2. 


\section{Conflict or coordination? Assessment of coordinated}

development between socioeconomic and ecological environment in resource-based cities: Evidence from Sichuan province of China

\section{Abstract}

The relationship between socioeconomic and ecological environment become a significant factor influencing the sustainable development of resource-based cities (RBCs), the transformation of RBCs is a key component of regional high-quality development. A comprehensive evaluation indicator system was constructed to research the coupling coordination level of RBCs in this paper, the dynamic DM model and the CCD model were adopted to measure the comprehensive level of the coupling coordination degree between socioeconomic and ecological environment of the 9 resource-based cities in Sichuan province. The results showed that the coupling coordination level was not ideal. Only two cities were located to the moderate coordination, and other cities were located to the primary coordination or tiny coordination. In addition, there was a significant different between SE and EE, and the comprehensive evaluation score of SE was lower than that of EE in eight RBCs, which accounting for $88.89 \%$. Based on this, the policy suggestions for the sustainable development of different type of RBCs were provided. This study offers a model of China's experience that might be benefit for achieving sustainable development goals (SGDs) of other cities and countries.

Key words: Socioeconomic; Ecological environment; Resource-based cities; Sichuan province; Coupling coordination degree.

\section{Introduction}

Resource-based cities (RBCs) are the core elements to promote the industrialization process in China. In general, the RBCs are cities that have enrichment energy resources, 
and the exploitation of energy or mineral resources are the core driving force for urban economic growth. However, due to the serious pollution caused by the exploitation of energy resources and the characteristics of non-renewable resources, the $\mathrm{RBCs}$ are faced with the challenge of how to take the road of green development. Statistical studies show that RBCs have the phenomenon of "resource curse", which means that the degree of resource abundance is inversely proportional to the level of sustainable economic growth (Yang and Song, 2019; Manzano and Gutiérrez, 2019; Zhang and Cui, 2020). The economic growth rate of resource-based cities usually changes from high to low in the rapid development of resource-based enterprises, but the ecological environment mostly shows the condition of gradual deterioration (Poncian, 2019; Adams et al., 2019). Breaking the traditional development mode and exploring a growth path that conforms to the coordinated development of socioeconomic and ecological environment has become a core issue for the transformation of RBCs.

The number of resource-based cities accounts for more than one third of all Chinese cities (The State Council of China, 2013). These cities have made significant contributions to China's industrialization path and economic growth. However, there are many environment and social problems caused by the exploitation of natural resources, such as industrial waste water pollution, mine vegetation destruction and mining area unemployment. As a resource-dependent city, the economic growth and social development of RBCs mainly depend on resource output, which presents an obvious phenomenon of "resource curse", and the long-term extensive economic growth model seriously restricts the industrial transformation and ecological environment optimization of RBCs (Zhang and Cui, 2020; Frynas and Buur, 2020). China's high-quality development model puts raise higher standard for urban economic growth and industrial transformation, and the sustainable development ability of RBCs that rely on traditional natural resources has become the focus of urban transformation (Huang et al., 2020; Hu et al., 2020). The key to China's urban economic transformation lies in the economically underdeveloped regions, especially the western regions of China such as Sichuan province. To realize the transformation and sustainable development goals of RBCs, the relationship between socioeconomic and ecological 
environment should be coordinated.

Based on the National Sustainable Development Plan of RBCs, there are four types of $\mathrm{RBCs}$, involving resource-growth cities, resource-mature cities, resource-depleted cities, and resource-regeneration cities (The Central people's Government of the People's Republic of China, 2013). This paper adopts the above classification to research the coupling coordination degree (CCD) between socioeconomic (SE) and ecological environment (EE) of nine RBCs in Sichuan province of China. Through the selection of evaluation model and construction of the theoretical framework (Fig. 1), the indicator system of CCD between SE and EE is determined. By comparing evaluation results of four types of cities, the key factors affecting different types of RBCs can be found out. In addition, it's worth noting that RBCs of China have significant similarities in their development paths and transformation modes, and the successful transformation experience of a single city can be quickly promoted to other cities. Therefore, the research on the four types of cities in Sichuan province is highly applicable to RBCs in other regions of China.

Based on previous studies on RBCs, the dynamic deviation maximization method and coupling coordination degree model are used to conduct empirical research (Fang et al., 2016; Li et al., 2020). This paper conducts case studies on the development paths of different types of RBCs in Sichuan province and discusses the CCD between SE and EE of RBCs in Western China. Among them, the resource-mature cities and resourcedepleted cities are the key points of urban transformation and sustainable development, which account for the highest proportion in China. The industries and economies of these cities are under pressure to transform. Therefore, the dilemma faced by RBCs in different periods are summarized in to provide reference for achieving the sustainable development goals (SDGs) of different types of RBCs. 

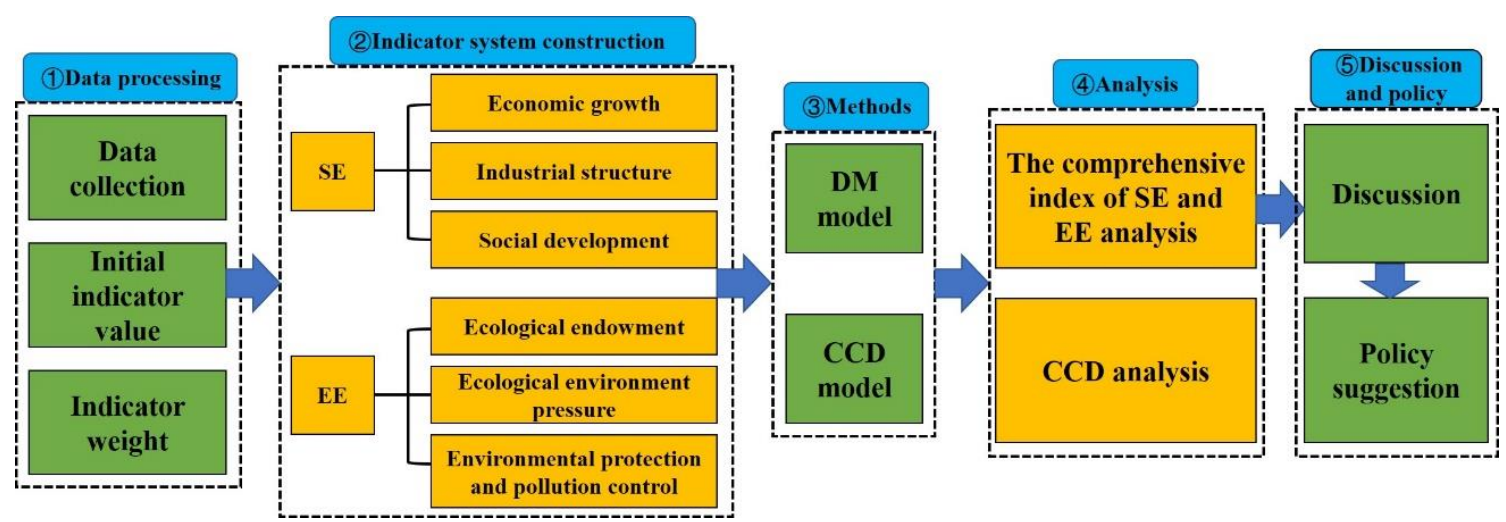

Fig. 1. Theoretical model proposed.

\section{Literature review}

The socioeconomic development of RBCs mainly depends on the natural resource exploitation, and the traditional economic growth model has caused tremendous pressure to the urban nature environment, including excessive urban sewage discharge, acid rain, air pollution and soil pollution. Coordinating the relationship between SE and EE has become a core issue to industrial transformation of RBCs (Xing et al., 2019; Liu et al., 2020). Existing researches on sustainable development of RBCs are mainly carried out from three aspects: (1) Urban innovation efficiency. The innovation of science and technology is the key factor of the transformation of RBCs (Lv et al., 2019), and the improvement of innovation efficiency mainly depends on the support of hightech industry and government policy (Yang et al., 2019; Tie et al., 2020). (2) Urban industrial transformation model and green transformation performance. Optimizing the industrial structure and strengthening technology investment in extensive enterprise of RBCs are the two mainly model to achieve industrial transformation (Kuai et al., 2015; Zhang et al., 2018; Xie et al., 2020). (3) Ecological vulnerability and ecological security of RBCs. The long-term mining of mines will pose tremendous pressure to the urban ecological security and ecological vulnerability degree of RBCs, which is the difficulty in realizing urban and industrial transformation in RBCs (Chen et al., 2019; He et al., 2020; Yang et al., 2020; Dai et al., 2020).

There are abundant studies on coupling between economic growth and ecological 
environment, but it's lacking of researching on the coordination between socioeconomic and ecological environment of different types of RBCs. For one thing, the ecological footprint model and the CDI are introduced to assess the comprehensive score of socioeconomic and ecological environment from the macro and meso perspective (Yang et al., 2019; Xu et al., 2019; Ariken et al., 2020), by measuring the comprehensive index of SE and EE between different regions, the harmonious relationship of sustainable development between regions and within regions is analyzed, which also verifies the existence of environmental Kuznets curve (Li et al., 2016; Pontarollo and Serpieri, 2020; Peng et al., 2020). For another, some studies have segmented economic development and researched the coupling and coordinated evolution of urban ecological environment from the perspectives of urban urbanization, land use and urban tourism development (Tang, 2015; Chai et al., 2017; Kurniawan et al., 2019; Wang et al., 2019; Yang et al., 2020).

Presently, many methods have been excavated to calculate the comprehensive index and the dynamic change rule of coordination relationship between SE and EE. Conventional evaluation methods mainly include the system dynamics model (Derwisch and Loewe, 2015; Elsawah et al., 2017; Li et al., 2020), grey relational analysis model (Wang et al., 2010; Li et al., 2012; Yang and Wu, 2019), fuzzy comprehensive evaluation method (Zeng et al., 2013; Xu and Li, 2019; Wen et al., 2021), the CCD model (Xu et al., 2019; Tao et al., 2020; Yang et al., 2020; Gan et al., 2020), the principal component analysis method (Fan et al., 2017; Li et al., 2020), the support vector machine method (Zhao and Lam, 2012; Zhao and Zhen, 2018), etc. Based on the above model referred, the CCD model (CCDM) is the most widely used method to estimate the variation of coupling coordination of multiple systems. The CCD refers to the measurement of the coordination relationship between two or more dynamically changing systems (Fu et al., 2020). The dynamic deviation maximization model and the $\mathrm{CCDM}$ are combined to measure the comprehensive coordination level of RBCs in Sichuan province in this paper.

Consistent with diversified application of evaluation methods, there is no consensus on the indicator system of coupling and coordination evaluation of socioeconomic and 
ecological environment has not been unified. For one thing, the socioeconomic evaluation of RBCs mainly involves economic growth (Li and Zhou, 2020), industrial structure (Tan et al., 2020), social employment (Tan et al., 2016), education level and medical care (Li et al., 2017), etc. For another, the ecological environment evaluation of RBCs includes ecological endowment (He et al., 2019), ecological environment pressure (Song et al., 2020), the environmental protection and pollution control (Wu et al., 2020). Therefore, both SE subsystem and EE subsystem contain many aspects of content. However, most of the existing researches on RBCs focus on the evaluation of a single city ( $\mathrm{Li}$ et al., 2016; He et al., 2019; Wang et al., 2020), and it's lacking of researching on dynamic assessment of the coordinated development of two or more systems of RBCs.

\section{Study area}

According to the National Sustainable Development Plan for RBCs (2013-2020), there are $262 \mathrm{RBCs}$ at the prefecture-level, county-level and municipal districts involved in the plan (State Council, 2013). And there are 102 RBCs in the Western China, which accounting for $38.93 \%$. The disequilibrium contradiction between socioeconomic and ecological environment is more significant due to the large area and the economically underdeveloped regions of Western China. For instance, the western region accounts for $20.71 \%$ of China's GDP in 2019, which is at a relatively low level. In addition, there are 9 prefecture-level RBCs in Sichuan province, which accounting for $42.86 \%$. The basic general situation of nine resource-based cities in Sichuan province are illustrated in Table 1.

The RBCs are divided into four types and the coordination levels between SE and EE are dynamically evaluated in this paper. Due to the lack of statistics at the county level, this paper selected 9 prefecture-level RBCs in Sichuan province as the research objects, including Nanchong, Zigong, Panzhihua, Guangyuan, Guangan, Dazhou, Yaan, Luzhou, Aba. The locations of the RBCs in Sichuan province are illustrated in Fig. 2. 


\begin{tabular}{lllll}
\hline City & Population & Area $\left(\mathrm{Km}^{2}\right)$ & Per-capita (Yuan) & Main resources \\
\hline Nanchong & $7,237,100$ & 12,477 & 36,073 & Oil, gas, gold, iron, uranium, phosphorus, salt \\
Zigong & $3,203,500$ & 4,381 & 48,904 & Coal, salt, gas, gold \\
Panzhihua & $1,083,700$ & 7,401 & 82,500 & Iron, vanadium, coal, chromium, gallium, scandium, nickel, copper \\
Guangyuan & $2,988,600$ & 16,311 & 35,262 & Coal, gold, silicon, graphite \\
Guangan & $4,593,000$ & 6,341 & 38,522 & Coal, gas, oil, iron, salt \\
Dazhou & $6,589,400$ & 16,582 & 30,982 & Coal, gas, iron, vanadium, salt \\
Yaan & $1,541,000$ & 15,046 & 46,984 & Coal, gas, iron, cobalt, manganese, titanium \\
Luzhou & $5,085,400$ & 12,236 & 48,105 & Coal, oil, gas, iron, copper, gold \\
Aba & 899,300 & 83,016 & 41,278 & Gold, lithium, iron, shale mine, coal \\
\hline
\end{tabular}
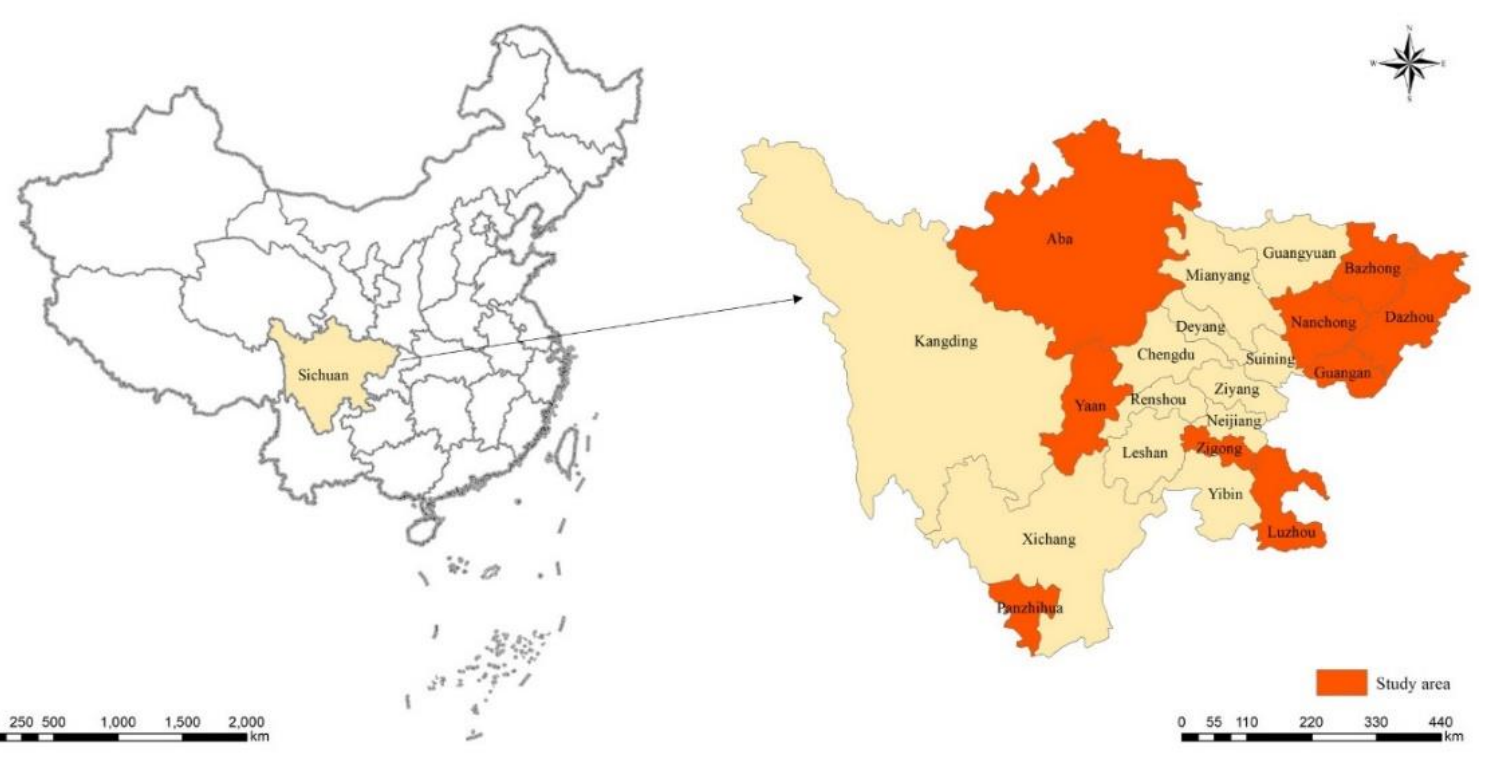

Fig. 2. The location of the 9 RBCs in Sichuan province.

\section{Methods}

\subsection{Construction of comprehensive index system}

The indicator system is established to scientifically reflect the comprehensive evaluation score of regional SE and EE subsystem in different perspectives. The selection of each indicator must abide by the principles of objectivity, scientific, comprehensive and accessibility. By referring to existing literature and considering the availability of research data, the indicator system established in this paper is shown in Table 2.

The SE subsystem contains three primary indicators and eleven second-level indicators.

The indicators "Per capita GDP", "Per capita disposable income of urban residents", 
"Per capita retail sales of consumer goods" and "Per capita export trade" were selected to reflect the urban economic growth and urban economic comprehensive level. The indicators "Proportion of secondary industry to GDP" and "Proportion of service industry to GDP" were used to reflected the dynamic changes of urban industrial structure. The indicator "Unemployment rate", "Urbanization rate", "Natural population growth rate", "Proportion of educational expenditure to the public finance" and "Number of doctors per 10,000 people" were selected to reflected the comprehensive score of employment, population growth, education development and medical-health services.

The EE subsystem includes three primary indicators and ten secondary indicators. This paper selected the four indicators "Forest coverage rate", "Per capita green area", "Green coverage rate in built-up areas", "Per capita arable land" to represent the regional ecological endowment. The indicators "Per capita discharged volume of industrial waste water", "Per capita discharged volume of industrial SO2" and "Per capita discharged volume of industrial dust" were used to measure the pollution pressure caused by industrial development to the ecological environment. Intensity of environmental regulation is an important guarantee for the quality of regional ecological environment. Therefore, the indicators "Sewage treatment rate", "Harmless disposal rate of household garbage" and "Comprehensive utilization rate of industrial solid waste" were used to explain the capability of environmental protection and governance.

It is noted that the secondary indicators demonstrated above cannot absolutely explain the comprehensive level in SE and EE of RBCs. For instance, the utilization rate of renewable energy, the utilization rate of non-renewable energy and the proportion of the output value of high-tech industries are important factors to measure the comprehensive sustainable development of RBCs. However, due to the unavailability of statistical data for some years of the study area. There, these indicators are not included in this paper.

Table 2

The indicator system of socioeconomic and ecological environment. 


\begin{tabular}{|c|c|c|c|c|}
\hline Subsystem & Primary indicators & Secondary indicators & Unit & Weight \\
\hline \multirow{11}{*}{$\begin{array}{c}\text { Socioeconomic } \\
\text { subsystem }\end{array}$} & \multirow[t]{4}{*}{ Economic growth } & Per capita GDP & Yuan & 0.219 \\
\hline & & Per capita disposable income of urban residents & Yuan & 0.085 \\
\hline & & Per capita retail sales of consumer goods & Yuan & 0.058 \\
\hline & & Per capita export trade & Yuan & 0.025 \\
\hline & \multirow[t]{2}{*}{ Industrial structure } & Proportion of secondary industry to GDP & $\%$ & 0.101 \\
\hline & & Proportion of service industry to GDP & $\%$ & 0.147 \\
\hline & \multirow[t]{5}{*}{ Social development } & Unemployment rate & $\%$ & 0.124 \\
\hline & & Urbanization rate & $\%$ & 0.054 \\
\hline & & Natural population growth rate & $\%$ & 0.033 \\
\hline & & Proportion of educational expenditure to the public finance & $\%$ & 0.087 \\
\hline & & Number of doctors per 10,000 people & 10,000 & 0.067 \\
\hline \multirow{10}{*}{$\begin{array}{l}\text { Ecological } \\
\text { environment } \\
\text { subsystem }\end{array}$} & \multirow[t]{4}{*}{ Ecological endowment } & Forest coverage rate & $\%$ & 0.027 \\
\hline & & Per capita green area & $\mathrm{m} 2$ & 0.027 \\
\hline & & Green coverage rate in built-up areas & $\%$ & 0.059 \\
\hline & & Per capita arable land & $\mathrm{m} 2$ & 0.041 \\
\hline & \multirow{3}{*}{$\begin{array}{l}\text { Ecological environment } \\
\text { pressure }\end{array}$} & Per capita discharged volume of industrial waste water & tons & 0.264 \\
\hline & & Per capita discharged volume of industrial $\mathrm{SO}_{2}$ & tons & 0.138 \\
\hline & & Per capita discharged volume of industrial dust & tons & 0.157 \\
\hline & Environmental & Sewage treatment rate & $\%$ & 0.175 \\
\hline & protection and pollution & Harmless disposal rate of household garbage & $\%$ & 0.081 \\
\hline & control & Comprehensive utilization rate of industrial solid waste & $\%$ & 0.031 \\
\hline
\end{tabular}

206 4.2. The dynamic deviation maximization method

207 In order to eliminate the effect of unit differences of indicator variables, the original

208 indicator variable $R_{i j}^{t k}$ needs to be standardized, and $R_{i j}^{t k}$ refers to the assessment

209 period $\boldsymbol{t}_{\boldsymbol{k}}$ of city $\boldsymbol{O}_{\boldsymbol{i}}$ on indicator ${ }^{I_{j}}$, where $i=1,2, \mathrm{~L}, n, j=1,2, \mathrm{~L}, m$,

$210 k=1,2, \mathrm{~L}, N$. The formula (1) was used to standardize the positive indicators, and

211 formula (2) was used to standardize the negative indicators.

$$
\begin{aligned}
Q_{i j}^{t k} & =\frac{R_{i j}^{t k}-\min \left(R_{i j}^{t k}\right)}{\max \left(R_{i j}^{t k}\right)-\min \left(R_{i j}^{t k}\right)} \\
Q_{i j}^{t k} & =\frac{\max \left(R_{i j}^{t k}\right)-R_{i j}^{t k}}{\max \left(R_{i j}^{t k}\right)-\min \left(R_{i j}^{t k}\right)}
\end{aligned}
$$

214 Where $Q_{i j}^{t k}$ represents the standardized matrix, $\max \left(Q_{i j}^{t k}\right)$ and $\min \left(Q_{i j}^{t k}\right)$ represents

215 the maximum value and the minimum value in the original matrix of indicator $\boldsymbol{I}_{j}$, 216 respectively. 
$\mathrm{w}=\left(w_{1}, w_{2}, \mathrm{~L}, w_{m}\right)^{T}$ represents the undetermined weights of $\boldsymbol{m}$ indicators. The weighted sum model (3) was adopted to assemble the standardized indicator values and the indicator weights.

$$
Z_{i}^{t k}=\sum_{j=1}^{m} Q_{i j}^{t k} w_{j}, \quad i=1,2, \mathrm{~L}, n
$$

221 Where $Z_{i}^{t k}$ represents the comprehensive evaluation score of cities $\boldsymbol{O}_{i}$ in the period $t_{k}$

The dynamic DM model was used for the purpose of assigning scientific weights to indicator variables, it can maximize the overall difference of decision scheme for each period, and the optimal decision scheme can be realized. Based on this, the programming model (4a) and (4b) were used to make decisions.

$$
\begin{aligned}
& \max \sum_{k=1}^{N} \sum_{i=1}^{n}\left(Z_{i}^{t k}-\bar{Z}\right)^{2} \\
& \text { s.t. }\left\{\begin{array}{l}
W^{T} W=1 \\
0 \leq w_{j} \leq 1
\end{array}\right\}
\end{aligned}
$$

Where $\bar{Z}$ is the average score of each evaluation results of all decision schemes, and $\bar{Z}$ is calculated by the formula (5).

$$
\bar{Z}=\frac{1}{N} \sum_{K=1}^{N}\left(\frac{1}{n} \sum_{i=1}^{n} Z_{i}^{t k}\right)
$$

The constraint condition $W^{T} W=1$ will cause the sum of each indicator weights not equal to 1 in the programming model (4a) and (4b). So, the final weight of each indicator was calculated by standardization treatment, and $w_{j}^{\prime}=w_{j} / \sum_{j=1}^{m} w_{j}$. Where $w_{j}$ was calculated by the model (4a) and (4b), and the final weight of each indicator were showed in the Table 2 . The variables ZSE and ZEE refers to the comprehensive evaluation score of SE and EE subsystem, respectively. The calculation process of CCD was as follows: 


$$
C=\frac{\sqrt{Z_{S E} \times Z_{E E}}}{\left(Z_{S E}+Z_{E E}\right) / 2}
$$

$$
T=\alpha Z_{S E}+\beta Z_{E E}
$$

$$
C C D=\sqrt{C \times T}
$$

Where $\mathrm{C}$ represents the coupling level of SE and EE. T refers to the evaluation scores of SE and EE, $\alpha$ and $\beta$ are undetermined coefficients of SE and EE, with $\alpha+\beta=1$ and $\alpha, \beta \in[0,1]$. In general, socioeconomic development as important as the ecological environment under urban sustainable development goals. Therefore, the value of $\alpha$ and $\beta$ are the same in this paper, $\alpha=\beta=0.5$.

The variable CCD refers to the comprehensive evaluation score of coupling coordination of RBCs, and the value range is $[0,1]$. The higher the evaluation value of CCD indicate that the higher the coupling coordination score and the higher the SE and EE comprehensive evaluation scores of research region. Conversely, the lower the evaluation value of CCD indicate that the lower the evaluation level. And there is no coupling coordination degree when the value of CCD is 0 , this is in contradiction with the development of urban reality (Yang and Na, 2019; Li et al., 2020).

\section{Results and findings}

The comprehensive evaluation results of SE in the 9 RBCs of Sichuan province showed significant differences (see the results shown in Table 3). From 2008 to 2018, the comprehensive level of the SE in Sichuan province presented an escalating trend, from 0.305 to 0.391 , with an increase of $28.20 \%$. However, the growth rate and growth range of the RBCs in Sichuan province were different, with significant spatial differences. It is shown that Panzhihua had the highest score and Guanyuan had the lowest score in socioeconomic development.

The evaluation scores of Nanchong increased from 0.292 to 0.351 during this period, and Nanchong is a resource-growth city with abundant mineral resources. The driving 

2932018.

force of socioeconomic development in Nanchong is the heavy exploration of oil, gas, iron, et al. As the oil and gas and energy chemical industry base in Sichuan province of western China, with the large-scale exploitation of natural resources, the SE of Nanchong has been rapidly promoted.

There are 6 prefecture-level resource-mature cities in Sichuan province. It is shown that the growth difference of SE in these cities is relatively significant. The evaluation scores of Zigong, Panzhihua, Guangyuan, Guangan, Dazhou and Yaan all showed an upward trend. The respective increases from 2008 to 2018 were $15.24 \%, 17.81 \%, 34.80 \%$, $22.78 \%, 41.67 \%$ and $12.14 \%$. As one of the four major iron mining areas in China, the resource reserves of associated titanium in Panzhihua accounted for 93\% of the country. From 2008 to 2018, the evaluation score increased from 0.657 to 0.774 in Panzhihua, which has the best comprehensive evaluation score in SE among the RBCs in Sichuan province. Guangyuan, Guangan and Dazhou lies in the northeast of Sichuan province, due to the long-term dependence on traditional mining and heavy industry, which leads to the relatively backward social and economic development. Although Northeast Sichuan is an important energy base in western China, industrial development has not brought significant social progress and development, and the evaluation scores in these cities were lower than other cities in Sichuan province.

The evaluation scores of Luzhou increased from 0.264 to 0.413 during the time, Luzhou is a resource-depletion city in Sichuan province. It can be seen from the calculation results that the socioeconomic development of Luzhou grew rapidly from 2016 to 2018, indicating that Luzhou is undergoing urban industrial transformation to promote the urban high-quality sustainable development. The evaluation scores of Aba increased from 0.273 to 0.424 , with an increase of $55.31 \%$.and Aba is a resource-regeneration city in Sichuan province. Tourism industry is gradually displacing the dominant role of extractive industries, and it takes the highest proportion.

\section{Table 3}

The comprehensive evaluation level of the SE in the 9 RBCs of Sichuan province from 2008 to

\begin{tabular}{lllllllllllll}
\hline City type & Year & 2008 & 2009 & 2010 & 2011 & 2012 & 2013 & 2014 & 2015 & 2016 & 2017 & 2018 \\
\hline Growth & Nanchong & 0.292 & 0.301 & 0.314 & 0.302 & 0.318 & 0.328 & 0.321 & 0.314 & 0.329 & 0.338 & 0.351
\end{tabular}




\begin{tabular}{llllllllllllll} 
Mature & Zigong & 0.315 & 0.322 & 0.339 & 0.331 & 0.319 & 0.332 & 0.312 & 0.315 & 0.345 & 0.357 & 0.363 \\
& Panzhihua & 0.657 & 0.682 & 0.701 & 0.748 & 0.752 & 0.753 & 0.755 & 0.760 & 0.761 & 0.765 & 0.774 \\
& Guangyuan & 0.204 & 0.216 & 0.218 & 0.223 & 0.234 & 0.245 & 0.254 & 0.259 & 0.261 & 0.268 & 0.275 \\
& Guangan & 0.259 & 0.265 & 0.272 & 0.269 & 0.263 & 0.264 & 0.265 & 0.287 & 0.295 & 0.313 & 0.318 \\
& Dazhou & 0.204 & 0.198 & 0.216 & 0.215 & 0.236 & 0.246 & 0.251 & 0.268 & 0.277 & 0.276 & 0.289 \\
& Yaan & 0.280 & 0.295 & 0.311 & 0.298 & 0.310 & 0.281 & 0.295 & 0.296 & 0.309 & 0.317 & 0.314 \\
Depletion & Luzhou & 0.264 & 0.295 & 0.318 & 0.310 & 0.335 & 0.346 & 0.328 & 0.327 & 0.411 & 0.434 & 0.413 \\
Regeneration & Aba & 0.273 & 0.328 & 0.408 & 0.372 & 0.406 & 0.376 & 0.393 & 0.398 & 0.412 & 0.415 & 0.424 \\
The region & & 0.305 & 0.323 & 0.344 & 0.341 & 0.353 & 0.352 & 0.353 & 0.358 & 0.378 & 0.387 & 0.391 \\
\hline
\end{tabular}

294 It is shown that the comprehensive evaluation score of EE in the 9 resource-based cities

295 of Sichuan province presented an increasing trend (Table 4), from 0.455 to 0.521 , with

296 an increase of $14.51 \%$. The EE evaluation score of Aba increase from 0.305 in 2008 to

2970.391 in 2018 , with an increase of $26.12 \%$, and the evaluation score of Aba is higher

298 than that of other RBCs in Sichuan province, the main reason is that Aba is a resource-

299 regeneration city, and its industrial development direction has changed to the tertiary

300 industry, which has strengthened the environmental regulation. Luzhou is the only city

301 with a decline trend in EE score in Sichuan province, the EE evaluation score of Luzhou

302 decrease from 0.449 in 2008 to 0.402 in 2018 , with a decrease of $-10.47 \%$, due to the

303 industrial structure dominated by extractive industry for a long time has increased the

304 pressure on ecological environment, which leads to some serious social or environment

305 problems such as excess energy, resource depletion, and ecological environmental

306 pollution.

307 The ecological environment score of resource-mature cities is better than that of 308 resource-growth and resource-depletion cities in Sichuan province from 2008 to 2018.

309 The evaluation score of EE in Nanchong, Zigong, Panzhihua, Guangyuan, Guangan,

310 Dazhou and Yaan showed an increase trend of fluctuating, the respective increases from

3112008 to 2018 were $35.90 \%, 24.22 \%, 10.81 \%, 10.17 \%, 23.06 \%, 1.38 \%$ and $16.83 \%$, the

312 main reason is that the intensity of environmental regulation has been gradually

313 strengthened in recent years, which has alleviated the ecological environmental

314 pollution caused by the vigorous development of the extractive industry and heavy

315 industry to some extent. However, it is shown that the evaluation results in EE scores

316 of resource-mature cities and resource-growth cities showed a trend of decline in many

317 years, the main reason is that some cities have not implemented environmental 
318 regulation policies and the local government has not provided support for the ecological

319 environment protection of large-scale mining areas.

$320 \quad$ Table 4

321 The comprehensive evaluation level of the EE in the 9 RBCs of Sichuan province from 2008 to 3222018.

\begin{tabular}{llllllllllllll}
\hline City type & Year & 2008 & 2009 & 2010 & 2011 & 2012 & 2013 & 2014 & 2015 & 2016 & 2017 & 2018 \\
\hline Growth & Nanchong & 0.312 & 0.297 & 0.265 & 0.259 & 0.290 & 0.308 & 0.357 & 0.348 & 0.416 & 0.402 & 0.424 \\
Mature & Zigong & 0.351 & 0.333 & 0.313 & 0.305 & 0.342 & 0.363 & 0.368 & 0.359 & 0.378 & 0.401 & 0.436 \\
& Panzhihua & 0.444 & 0.389 & 0.375 & 0.343 & 0.384 & 0.436 & 0.452 & 0.476 & 0.482 & 0.490 & 0.492 \\
& Guangyuan & 0.541 & 0.598 & 0.572 & 0.611 & 0.564 & 0.567 & 0.560 & 0.571 & 0.577 & 0.584 & 0.596 \\
& Guangan & 0.464 & 0.440 & 0.525 & 0.520 & 0.504 & 0.516 & 0.524 & 0.511 & 0.536 & 0.559 & 0.571 \\
& Dazhou & 0.506 & 0.507 & 0.489 & 0.525 & 0.492 & 0.498 & 0.507 & 0.516 & 0.510 & 0.499 & 0.513 \\
& Yaan & 0.517 & 0.498 & 0.503 & 0.527 & 0.540 & 0.556 & 0.585 & 0.587 & 0.573 & 0.584 & 0.604 \\
\multirow{2}{*}{$\begin{array}{l}\text { Depletion } \\
\text { Regeneration }\end{array}$} & Luzhou & 0.449 & 0.374 & 0.341 & 0.351 & 0.369 & 0.370 & 0.394 & 0.377 & 0.390 & 0.370 & 0.402 \\
The region & Aba & 0.513 & 0.569 & 0.592 & 0.597 & 0.603 & 0.601 & 0.615 & 0.624 & 0.640 & 0.639 & 0.647 \\
\hline
\end{tabular}

323 The dynamic changes of the CCD of the 9 resource-based cities are shown in Fig. 3.

324 The results showed that the comprehensive evaluation level of the CCD in the 9

325 resource-based cities in Sichuan province showed an upward trend (Table 5), from

3260.563 to 0.635 , with an increase of $12.79 \%$. The CCD evaluation score of Panzhihua

327 increase from 0.714 in 2008 to 0.756 in 2018 , with an increase of $5.89 \%$, and the

328 evaluation score of Panzhihua is higher than that of other cities, the main reason are as

329 follows. The development of the extractive industry in Panzhihua is an important force

330 to promote the industrialization of western China. It is rich in natural resources such as

331 coal, steel and vanadium and titanium, and it has the highest per capita GDP in Sichuan

332 province. The comprehensive evaluation score of the CCD in the resourced-based cities

333 of Sichuan province was not ideal. There are eight cities showed a downward trend in

334 some year, involving Nanchong, Zigong, Panzhihua, Guangan, Dazhou, Yaan, Luzhou

335 and Aba, accounting for $88.89 \%$ (Fig. 3.). Only Guangyuan showed a gradual upward

336 trend from 2008 to 2018.

$337 \quad$ Table 5

338 The comprehensive evaluation level of the CCD in the 9 RBCs of Sichuan province from 2008 to 3392018.

\begin{tabular}{llllllllllllll}
\hline City type & Year & 2008 & 2009 & 2010 & 2011 & 2012 & 2013 & 2014 & 2015 & 2016 & 2017 & 2018 \\
\hline Growth & Nanchong & 0.549 & 0.547 & 0.534 & 0.526 & 0.550 & 0.563 & 0.581 & 0.574 & 0.602 & 0.604 & 0.617 \\
Mature & Zigong & 0.575 & 0.572 & 0.570 & 0.563 & 0.574 & 0.588 & 0.579 & 0.578 & 0.600 & 0.614 & 0.627
\end{tabular}




\begin{tabular}{lllllllllllll} 
& Panzhihua & 0.714 & 0.677 & 0.667 & 0.636 & 0.675 & 0.716 & 0.728 & 0.745 & 0.749 & 0.754 & 0.756 \\
& Guangyuan & 0.485 & 0.497 & 0.502 & 0.506 & 0.524 & 0.537 & 0.547 & 0.553 & 0.555 & 0.563 & 0.571 \\
& Guangan & 0.553 & 0.557 & 0.568 & 0.565 & 0.558 & 0.560 & 0.560 & 0.582 & 0.590 & 0.608 & 0.613 \\
& Dazhou & 0.488 & 0.480 & 0.505 & 0.502 & 0.529 & 0.540 & 0.545 & 0.563 & 0.572 & 0.570 & 0.584 \\
& Yaan & 0.576 & 0.589 & 0.603 & 0.593 & 0.604 & 0.578 & 0.591 & 0.592 & 0.605 & 0.612 & 0.610 \\
Depletion & Luzhou & 0.557 & 0.570 & 0.573 & 0.573 & 0.592 & 0.598 & 0.596 & 0.591 & 0.632 & 0.630 & 0.638 \\
Regeneration & Aba & 0.568 & 0.621 & 0.683 & 0.659 & 0.683 & 0.662 & 0.675 & 0.680 & 0.691 & 0.693 & 0.700 \\
The region & & 0.563 & 0.568 & 0.578 & 0.569 & 0.588 & 0.593 & 0.600 & 0.606 & 0.622 & 0.628 & 0.635 \\
\hline
\end{tabular}

340 The CCD comprehensive level of RBCs in Sichuan province was divided into five

341 grades in this paper, as shown in Fig. 4. The level I represents good coordination with

342 the CCD value range of $[0.8,0.9)$. In the level II, the value range of CCD is $[0.7,0.8)$,

343 indicating the moderate coordination. The value range of CCD in the evaluation city is

$344[0.6,0.7)$, which indicates primary coordination. It is divided into the level IV when the

$345 \mathrm{CCD}$ value of the evaluation city is $[0.5,0.6)$, indicating tiny coordination. The level V

346 represents the mild dissonance with the CCD value range of $[0.4,0.5)$.

347 It is shown that there is no city in level I and level III in 2008, and only one city located

348 to the level of moderate coordination, six RBCs are located to the level of tiny

349 coordination, accounting for $66.67 \%$. Besides, there are two cities located to the level

350 of mild dissonance. In terms of 2018, the results showed that there is no city in level I

351 and level $\mathrm{V}$, and the number of cities with moderate coordination increased from one

352 in 2008 to two in 2018 , the number of cities with primary coordination increased form

353 zero in 2008 to five in 2018 . Besides, the number of cities with tiny coordination

354 decreased from 6 in 2008 to 2 in 2018. It indicates that there is an unbalanced

355 development level in SE and EE of the 9 RBCs in Sichuan province. Although some

356 RBCs were located to the coordination level, the coordination degree showed decline

357 trend in some year. The main reason is that the comprehensive evaluation level of SE

358 in most RBCs was far behind that of EE in Sichuan province, this can be seen from

359 Table 3 and Table 4, and it can also be more clearly seen from Table 6.

360 Table 6

361 The growth rate and difference in SE and EE of the 9 RBCs in Sichuan province of China.

\begin{tabular}{llllll}
\hline City & M-SE* & M-EE* & Difference** & SE Growth rate $(\%)$ & EE Growth rate $(\%)$ \\
\hline Nanchong & 0.319 & 0.334 & 0.015 & 20.21 & 35.90 \\
Zigong & 0.332 & 0.359 & 0.027 & 15.24 & 24.09 \\
Panzhihua & 0.737 & 0.433 & 0.304 & 17.81 & 10.72
\end{tabular}




\begin{tabular}{llllll} 
Guangyuan & 0.242 & 0.576 & 0.335 & 34.94 & 10.13 \\
Guangan & 0.279 & 0.515 & 0.236 & 22.82 & 23.06 \\
Dazhou & 0.243 & 0.506 & 0.262 & 41.67 & 1.31 \\
Yaan & 0.301 & 0.552 & 0.252 & 12.01 & 16.76 \\
Luzhou & 0.344 & 0.381 & 0.037 & 56.67 & -10.52 \\
Aba & 0.382 & 0.604 & 0.221 & 55.38 & 26.14 \\
\hline
\end{tabular}

362 Note: M-SE* and M-EE* indicate the average value of SE and EE from 2008 to 2018, respectively; Difference**

363 indicate the absolute deviation between M-SE and M-EE of the city; SE Growth rate and EE Growth rate indicate

364 the absolute growth rate of SE and EE from 2008 to 2018, respectively.

365 Table 6 showed that there were three cities had little different of the two subsystems in

366 Sichuan province, involving Nanchong, Zigong and Luzhou. From the average level of

367 the results, it is shown that only the SE of Panzhihua was better than EE. For the other

368 eight RBCs, their evaluation level of CCD was lower than that of EE, which accounting

369 for $88.89 \%$. It is noted that there was a significant difference between SE and EE in

370 Panzhihua and Guangyuan, with their absolute deviation value above 0.3. For one thing,

371 from the perspective of SE growth rate, there were six cities had the growth rate of more

372 than 20\%, including Nanchong, Guangyuan, Guangan, Dazhou, Luzhou and Aba. And

373 it showed that there was a significant difference of the SE growth rate between RBCs

374 in Sichuan province. For another, form the perspective of EE growth rate, there were

375 four cities had the growth rate of more than $20 \%$, involving Nanchong, Zigong,

376 Guangan and Aba, Luzhou was the only city with the negative growth rate.

377 The reason for the backward development of SE lies in the unbalanced development of

378 regional economy and the single industrial structure. The economic growth of these

379 cities depends on the development of long-term extractive industries and heavy

380 industries. However, as these industries put increasing pressure on the ecological

381 environment, which leads to more serious contradictions between SE and EE. In

382 addition, the problem of overcapacity in these cities is prominent under the high-quality

383 development, which leads to some serious social problems, such as the rise of social

384 unemployment rate, unstable income of residents, burden of the government's social

385 security expenditure, et al. By analyzing the initial values of each indicator, it is found

386 that the loss of labor force and the slow growth rate of population were the two

387 important factors affecting the lagging development of SE. 


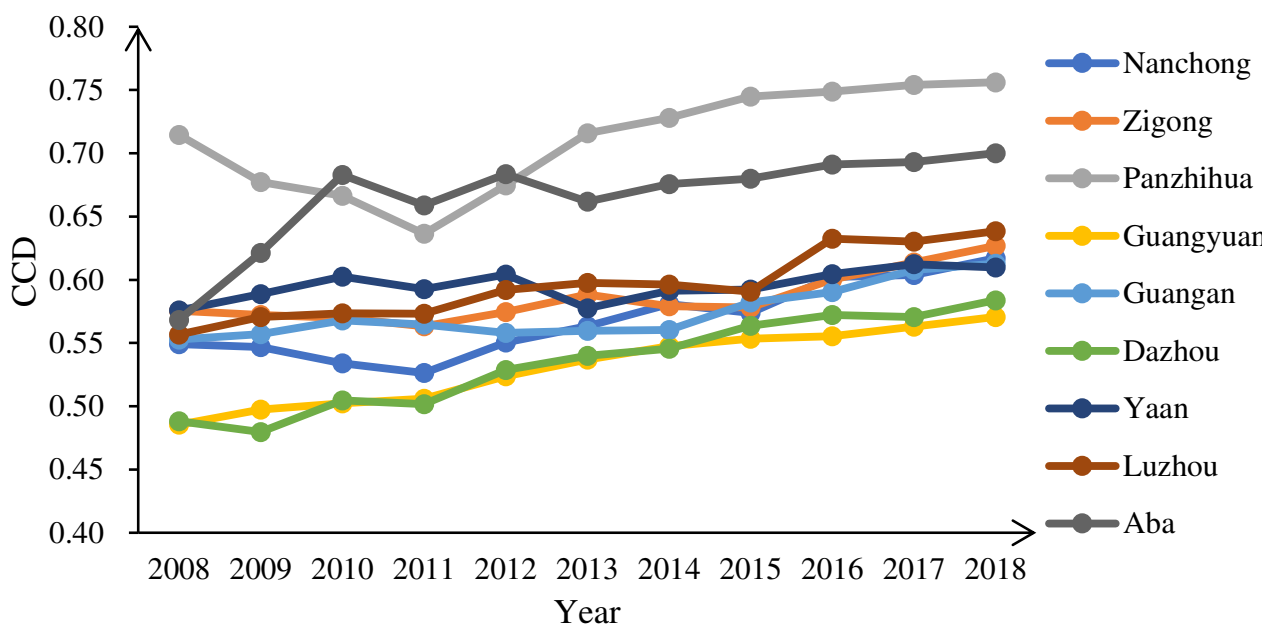

Fig. 3. The dynamic change of the CCD of the 9 RBCs in the year 2008-2018.

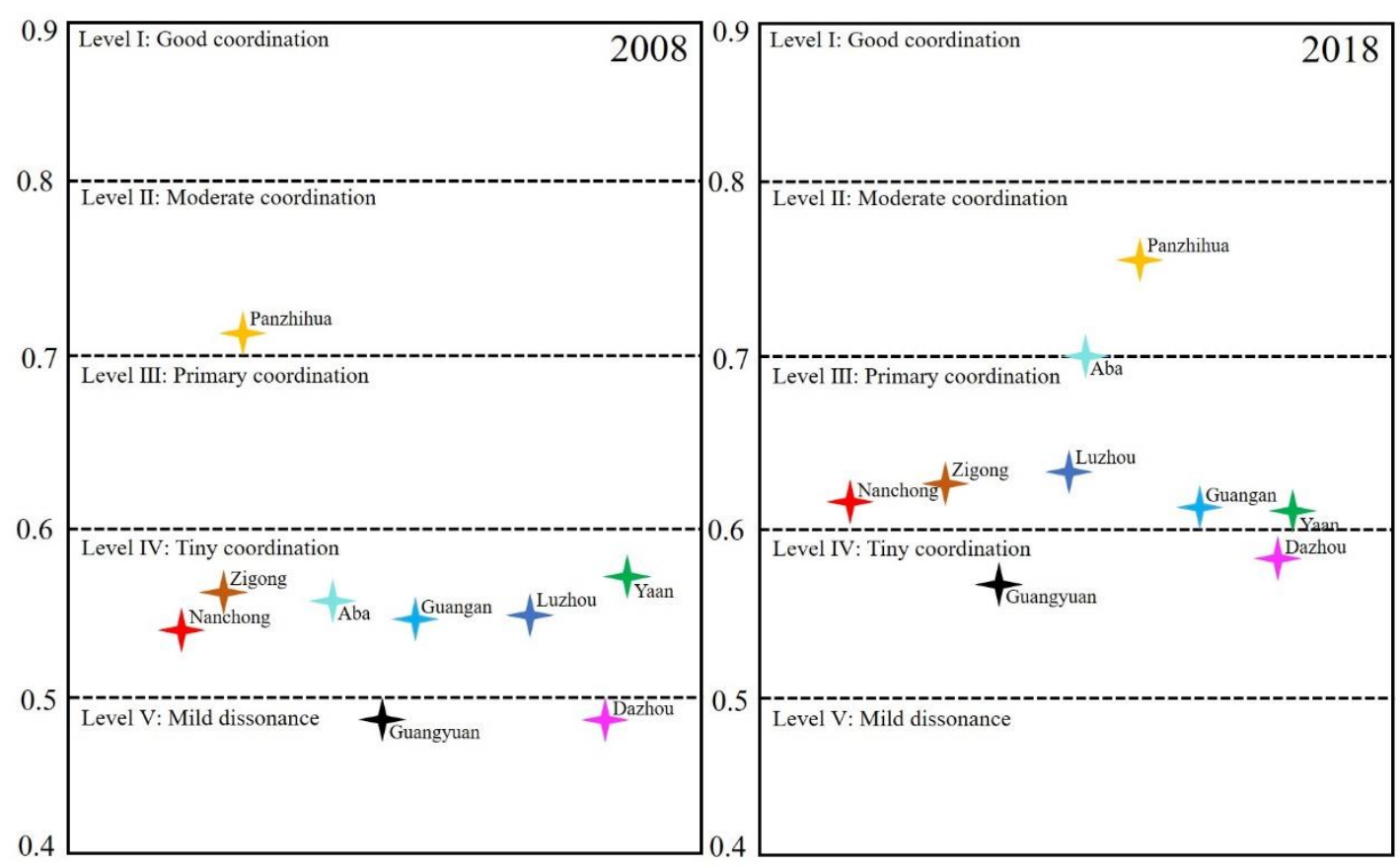

Fig. 4. The grade division of the RBCs in 2008 and 2018.

\section{Conclusion and policy suggestion}

The CCD model and the dynamic DM model were adopted to evaluate the coupling coordination degree between socioeconomic (SE) and ecological environment (EE) of RBCs in Sichuan province. The evaluation results showed that the CCD of the nine RBCs in Sichuan province was not ideal, and there was a significant different between SE and EE. It can be summarized in the following two aspects. On the one hand, seven cities were located to the level of primary coordination, tiny coordination, and mild 
dissonance, which accounting for $77.78 \%$. and only two cities were located to the level of moderate coordination. In addition, there was a decline trend of the CCD in some years. On the other hand, the evaluation score of SE in eight cities was far behind that of EE in Sichuan province, which accounting for $88.89 \%$, and there were six cities showed significant difference between SE and EE. It is found that the backward development of SE was the main obstacle to the uncoordinated development of RBCs. According to the above analysis of the SE and EE, this paper puts forward four policy suggestions for urban and industrial transformation of RBCs. First, Improving the policy and financial support for the tertiary industry to optimize the industrial structure, especially for the high-tech industry and green industry. Second, high-new technology should be promoted to improve the social production efficiency of extractive industry and heavy industry to reduce the pollution to the ecological environment. Third, the government should strengthen the guidance of industrial layout and gradually get rid of the dependence on resource development through policy guidance. Finally, solving the problem of unemployment and labor loss caused by mine closure, the government should raise the basic salary level of local employees and optimize the environment for innovation and entrepreneurship to improve the government's public service capacity.

In terms of different types of RBCs, resourced-growth cities and resourced-mature cities have great potential for resource exploitation, to avoid the transition to resourcedepletion cities, the adjustment of industrial structure should be strengthened to decrease the dependence on resource exploitation in the process of urban transformation. In addition, these cities should pay more attention to environmental protection and pollution control. For resource-depletion cities, the labor loss is the key problem to affect the comprehensive development of RBCs, the government should take measures to increase employment rate, such as increasing the wages of employees and improving the welfare level of employees in local enterprises. For resource-regeneration cities, these cities should continue to improve the level of industrial upgrading in order to drive and radiate the transformation of surrounding cities. 
Authors' Contributions Yi Xiao: Conceptualization, Investigation, Methodology, Writing-review \& editing, Roles/Writing-original dra; Yuan Li: Formal analysis, Validation, Visualization, Software; Supervision; Huan Huang: Data curation, Project administration, Resources.

Funding This work was supported by the National Natural Science Foundation of China (41790445, 42042019); Independent Project Foundation of State Key Laboratory (SKLGP2015Z004); Social Science Foundation of Chengdu University of Technology (YJ2017-JD003、YJ2019-JX004).

Data availability The datasets used during the current study are available from the corresponding author on reasonable request.

\section{Compliance with ethical standards}

Conflict of interest The author declare that they have no competing interests.

Ethical approval Not applicable.

Consent to participate Not applicable.

Consent to publish Not applicable.

\section{Reference}

Adams, D., Adams, K., Ullah, S., 2019. Globalisation, governance, accountability and the natural resource 'curse': Implications for socio-economic growth of oil-rich developing countries. Resources Policy (61), 128-140.

Ariken, M., Zhang, F., Liu, K., 2020. Coupling coordination analysis of urbanization and eco-environment in Yanqi Basin based on multi-source remote sensing data. Ecological indicators (114), 106331 .

Chai, J., Wang, Z. Q., Zhang, H. W., 2017. Integrated Evaluation of Coupling Coordination for Land Use Change and Ecological Security: A Case Study in Wuhan City of Hubei Province, China. International Journal of Environmental Research and 
Public Health 14 (11), 1435.

Chen, X., Xu, D. W., Fadelelseed, S., 2019. Spatiotemporal Analysis and Control of Landscape Eco-Security at the Urban Fringe in Shrinking Resource Cities: A Case Study in Daqing, China. International Journal of Environmental Research and Public Health 16 (23), 4640.

Dai, X., Gao, Y., He, X., 2020. Spatial-temporal pattern evolution and driving force analysis of ecological environment vulnerability in Panzhihua City. Environmental Science and Pollution Research 28 (06), 7151-7166.

Derwisch, S., Loewe, P., 2015. Systems Dynamics Modelling in Industrial Development Evaluation. IDS Bulletin 46 (1), 44-57.

Elsawah, S., Pierce, S. A., Hamilton, S. H., 2017. An overview of the system dynamics process for integrated modelling of socio-ecological systems: Lessons on good modelling practice from five case studies. Environmental Modelling and Software $93(7), 127-145$.

Fang, C., Liu, H., Li, G., 2016. International progress and evaluation on interactive coupling effects between urbanization and the eco-environment. Journal of Geographical Sciences 26 (8), 1081-1116.

Fan, S., Zhang, Y., Zhang, Y., 2017. Motion process monitoring using optical flowbased principal component analysis-independent component analysis method. Advances in Mechanical Engineering 9(11):168781401773323.

Frynas, J. G., Buur, L., 2020. The presource curse in Africa: Economic and political effects of anticipating natural resource revenues. The Extractive Industries and Society 7 (04), 1257-1270.

Fu, S., Zhuo, H., Song, H., 2020. Examination of a coupling coordination relationship between urbanization and the eco-environment: a case study in Qingdao, China. Environmental Science and Pollution Research 27 (19), 23981-23993.

Gan, L., Shi, H., Hu, Y., 2020. Coupling coordination degree for urbanization cityindustry integration level: Sichuan case. Sustainable Cities and Society 58, 102136.

Huang, X., Cai, B., L, Y. L., 2020. Evaluation Index System and Measurement of High-quality Development in China. Revista De Cercetare Si Interventie Sociala 68, 
163-178.

Hu, H., Ma, Y., Wu, S., 2020. Fuzzy comprehensive evaluation on high-quality development of China's rural economy based on entropy weight. Journal of Intelligent and Fuzzy Systems 38 (4), 1-9.

He, G., Bao, K., Wang, W., 2019. Assessment of ecological vulnerability of resource-based cities based on entropy-set pair analysis. Environmental Technology 20.

Kurniawan, F., Adrianto, L., Bengen, D. G., 2019. The social-ecological status of small islands: An evaluation of island tourism destination management in Indonesia. Tourism Management Perspectives 31, 136-144.

Kuai, P., Li, W., Cheng, R., 2015. An application of system dynamics for evaluating planning alternatives to guide a green industrial transformation in a resourcebased city. Journal of Cleaner Production 104, 403-412.

Liu, B., Wang, J., Jing, Z., 2020. Measurement of sustainable transformation capability of resource-based cities based on fuzzy membership function: A case study of Shanxi Province, China. Resources Policy 68, 101739.

Lv, L. C., Sun, F. X., Huang, R., 2019. Innovation-based urbanization: Evidence from 270 cities at the prefecture level or above in China. Journal of Geographical Sciences 29(008), 1283-1299.

Li, X., Yan, X., An, Q., 2016. The coordination between China's economic growth and environmental emission from the Environmental Kuznets Curve viewpoint. Natural Hazards 83 (1), 233-252.

Li, R., Zhu, Q., Kiely, J., 2020. Algorithms for U-Model-Based Dynamic Inversion (UM-Dynamic Inversion) for Continuous Time Control Systems. Complexity 2020 (91), $1-14$.

Li, Q. F., Dang, Y. G., Wang, Z. X., 2012. Analysis of the Regional Coordination Development Systems based on GRA and GM $(1$, N). Journal of Grey System 24 (01), 95-100.

Li, L., Zhao, J., Wang, C., 2020. Comprehensive evaluation of robotic global performance based on modified principal component analysis. International Journal of Advanced Robotic Systems, 17 (4), 172988141989688. 

Growth from Environment Costs in China's Resource-Based Cities. Mathematical Problems in Engineering, 2020, 1283740. Resource-Based Cities Based on the DEA Approach: A Case Study of Jiaozuo, China. Mathematical Problems in Engineering 2016, 1-10.

Li, B., Dewan, H., 2017. Efficiency differences among China's resource-based cities and their determinants. Resources Policy 51, 31-38.

Li, W., Yi, P., Zhang, D., 2020. Assessment of coordinated development between social economy and ecological environment: Case study of resource-based cities in Northeastern China. Sustainable Cities and Society 59, 102208.

Manzano, O., Gutiérrez, J. D., 2019. The subnational resource curse: theory and evidence. The Extractive Industries and Society 6 (2), 261-266.

Pontarollo, N., Serpieri, C., 2020. Testing the Environmental Kuznets Curve hypothesis on land use: The case of Romania. Land Use Policy 97, 104695.

Peng, B., Sheng X., Wei, G., 2020. Does environmental protection promote economic development? From the perspective of coupling coordination between environmental protection and economic development. Environmental Science and Pollution Research 27 (31), 39135-39148.

Poncian, J., 2019. Extractive resource ownership and the subnational resource curse: Insights from Tanzania. The Extractive Industries and Society 6 (2), 332-342.

Song, M., Zhao, X., Shang, Y., 2020. Realization of green transition based on the anti-driving mechanism: An analysis of environmental regulation from the perspective of resource dependence in China. The Science of the Total Environment 698, 134317.

State Council (2013). National sustainable development plan for resource-based cities (2013-2020). http://www.gov.cn/gongbao/content/2013/content_2547140.htm.

Tang, Z., 2015. An integrated approach to evaluating the coupling coordination between tourism and the environment. Tourism Management 46, 11-19.

Tan, J. T., Zhang, P. Y., Kevin, L., 2016. The Urban Transition Performance of Resource-Based Cities in Northeast China. Sustainability 8 (10), 1022. 
Shi, Tao., Yang, S. Y., Zhang, W., 2020. Coupling coordination degree measurement and spatiotemporal heterogeneity between economic development and ecological environment--Empirical evidence from tropical and subtropical regions of China. Journal of Cleaner Production 244, 118739-118739.

Tan, J. T., Hu, X. H., Hassink, R., Ni, J. W., 2020. Industrial structure or agency: What affects regional economic resilience? Evidence from resource-based cities in China. Cities 106, 102906.

Tie, M., Qin, M., Song, Q. J., 2020. Why does the behavior of local government leaders in low-carbon city pilots influence policy innovation?. Resources, Conservation and Recycling, 152, 104483.

Wang, Q., Zhang, D., Hu, H., 2010. Grey Relational Analysis Method of Linguistic Information and Its Application in Group Decision. Advances in Grey Systems Research. Springer Berlin Heidelberg.

Wen, Q. M., Liu, G., Wu, W. 2021. Multicriteria comprehensive evaluation framework for industrial park-level distributed energy system considering weights uncertainties, Journal of Cleaner production 282, 124530.

Wang, Z., Liang, L., Sun, Z., 2019. Spatiotemporal differentiation and the factors influencing urbanization and ecological environment synergistic effects within the Beijing-Tianjin-Hebei urban agglomeration. Journal of Environmental Management $243,227-239$.

Wu, X., Zhang, J. J., Geng, X. L., 2020. Increasing green infrastructure-based ecological resilience in urban systems: A perspective from locating ecological and disturbance sources in a resource-based city. Sustainable Cities and Society 61, 102354.

Wang, D., Shi, Y., Wan, K., 2020. Integrated evaluation of the carrying capacities of mineral resource-based cities considering synergy between subsystems. Ecological Indicators 108, 105701.

Xu, Y., Li, A., 2019. Regional economic development coordination management system based on fuzzy hierarchical statistical model. Neural Computing and Applications 31 (12), 8305-8315.

Xu, M., Chen, C., Deng, X., 2019. Systematic analysis of the coordination degree 
of China's economy-ecological environment system and its influencing factor. Environmental Science and Pollution Research 26 (29), 29722-29735.

Xie, W. C., Yan, T. H., Xia, S. M., 2020. Innovation or Introduction? The Impact of Technological Progress Sources on Industrial Green Transformation of ResourceBased Cities in China. Frontiers in Energy Research 8, 598141.

Xing, L., Xue, M., Hu, M., 2019. Dynamic simulation and assessment of the coupling coordination degree of the economy-resource-environment system: Case of Wuhan City in China. Journal of Environmental Management 230, 474-487.

Yang, Q., Song, D., 2019. How does environmental regulation break the resource curse: Theoretical and empirical study on China. Resources Policy 64, 101480. Yang, Y., Na, H., 2019. The spatial and temporal evolution of coordinated ecological and socioeconomic development in the provinces along the Silk Road Economic Belt in China. Sustainable Cities and Society 47, 101466.

Yang, H., Zhai, G., Zhang, Y., 2020. Ecological vulnerability assessment and spatial pattern optimization of resource-based cities: A case study of Huaibei City, China. Human and Ecological Risk Assessment 2020 (11), 1-20.

Yang, C., Zeng, W., Yang, X., 2020. Coupling coordination evaluation and sustainable development pattern of geo-ecological environment and urbanization in Chongqing municipality, China. Sustainable Cities and Society 61, 102271.

Yang, W., Wu, Y. A., 2019. Novel TOPSIS Method Based on Improved Grey Relational Analysis for Multiattribute Decision-Making Problem. Mathematical Problems in Engineering 2019, 8761681.

Yang, Y. Y., Bao, W. K., Liu, Y. S., 2020. Coupling coordination analysis of rural production-living-ecological space in the Beijing-Tianjin-Hebei region. Ecological Indicators 117,106512

Zhang, Y., Cui, M., 2020. Determining the innovation efficiency of resource-based cities using a relational network DEA model: evidence from china. The Extractive Industries and Society 7 (4), 1557-1566.

Zhao, J., Jin, Z., 2018. Predict coordinated development degree of county ecoenvironment system using GA-SVM: A case study of Guanzhong urban agglomeration. 
604 Journal of Global Information Management 26 (3), 1-10.

605 Zhao, J., Lam, K. P., 2012. Influential factors analysis on LEED building markets

606 in U.S. East Coast cities by using Support Vector Regression. Sustainable Cities and 607 Society 5, 37-43.

608 Zeng, W. Y., Feng, S., 2013. An improved comprehensive evaluation model and 609 its application. International Journal of Computational Intelligence Systems 7 (4), 706610714.

611 Zhang, H. M., Xiong, L. F., Li, L. S., Zhang, S. F., 2018. Political incentives, 612 transformation efficiency and resource-exhausted cities. Journal of Cleaner Production $613 \quad 196,1418-1428$. 


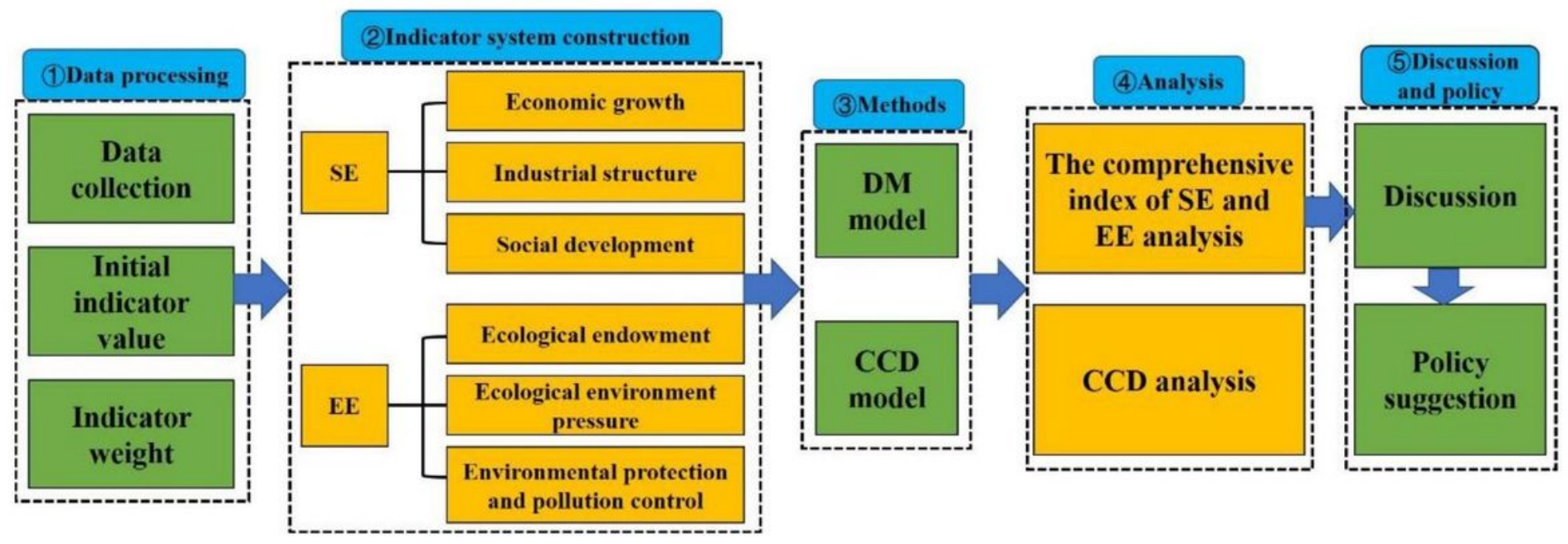

\section{Figure 1}

Theoretical model proposed.
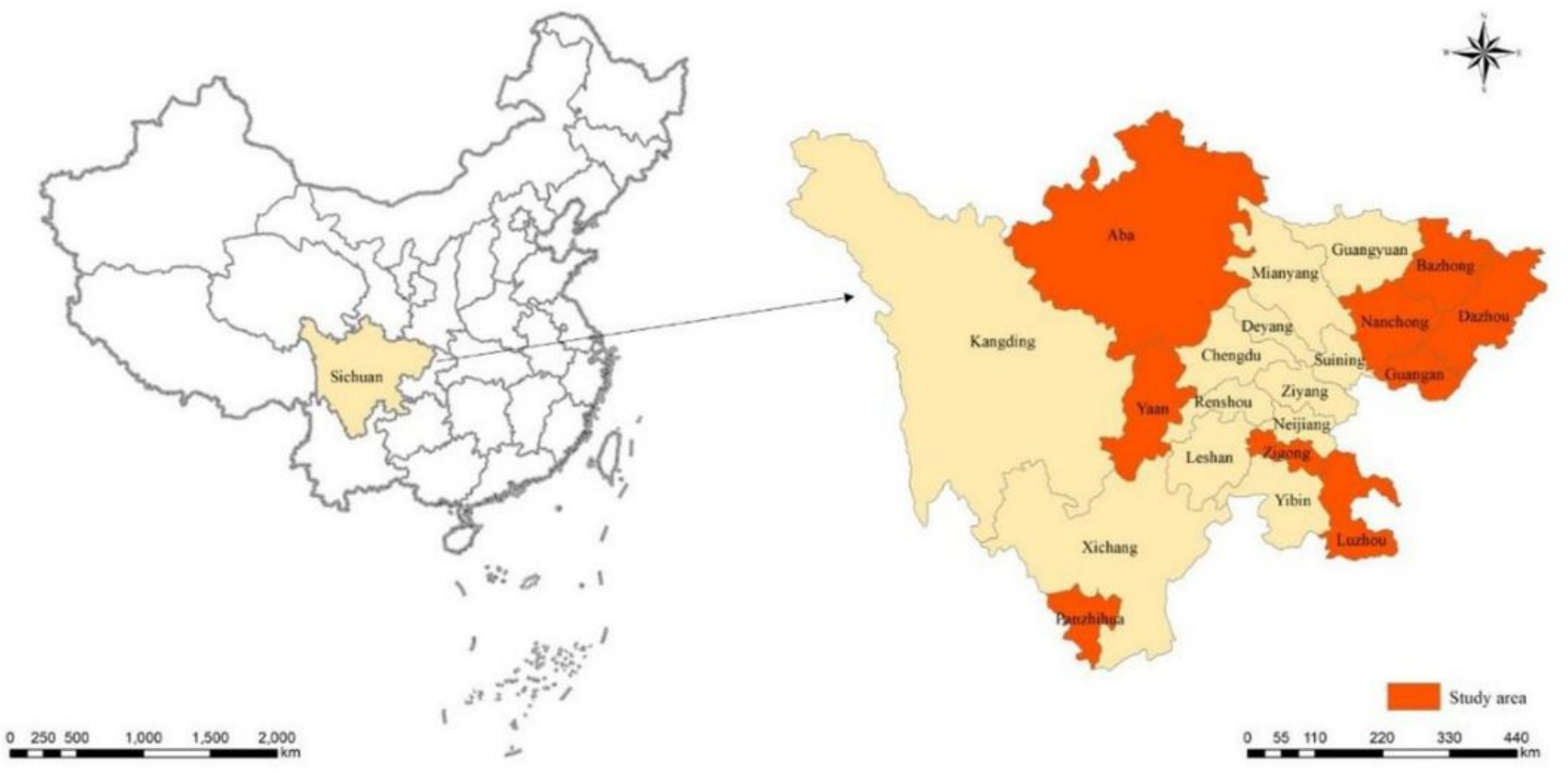

\section{Figure 2}

The location of the 9 RBCs in Sichuan province. Note: The designations employed and the presentation of the material on this map do not imply the expression of any opinion whatsoever on the part of Research Square concerning the legal status of any country, territory, city or area or of its authorities, or concerning the delimitation of its frontiers or boundaries. This map has been provided by the authors. 


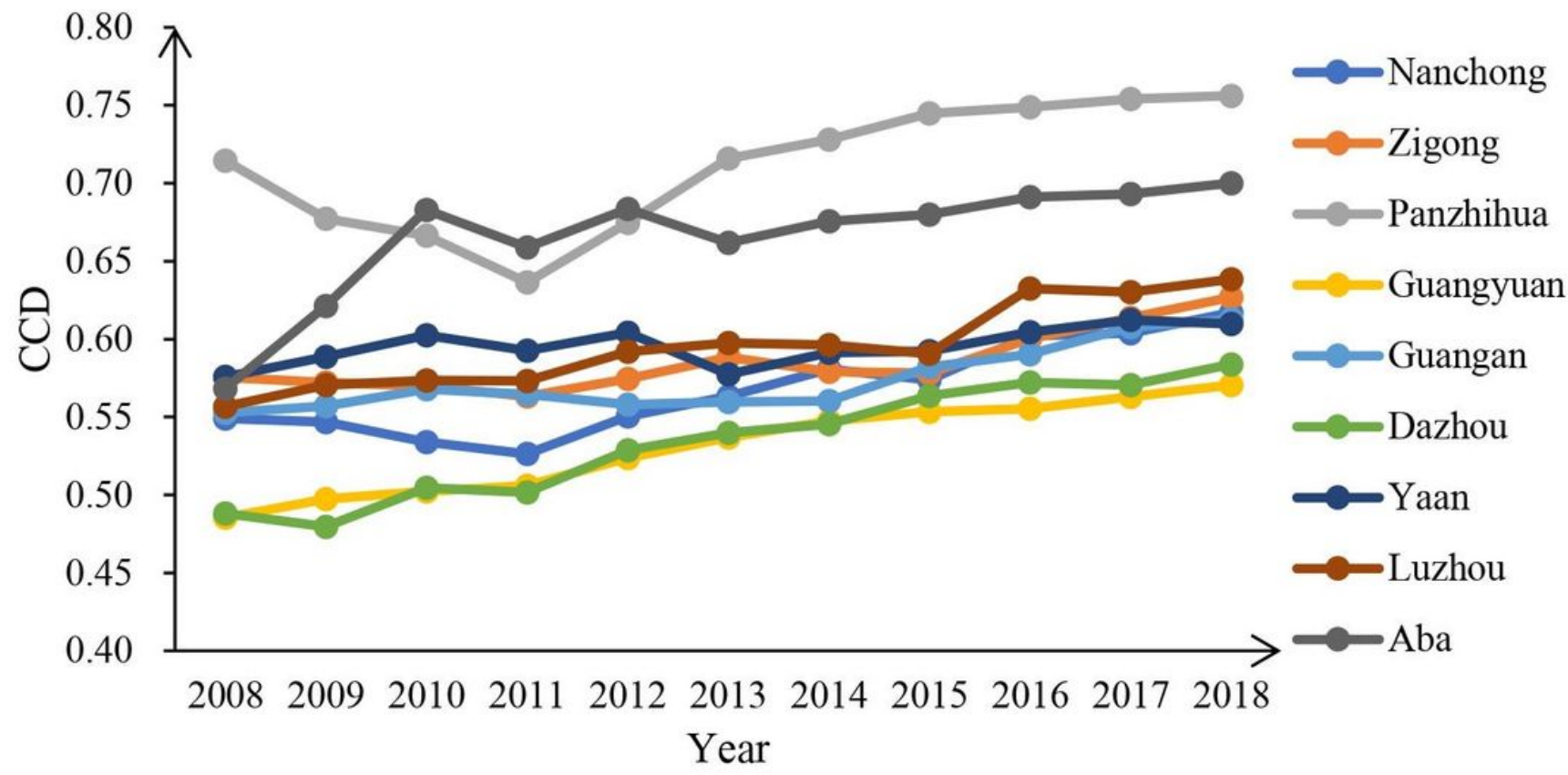

Figure 3

The dynamic change of the CCD of the 9 RBCs in the year 2008-2018.

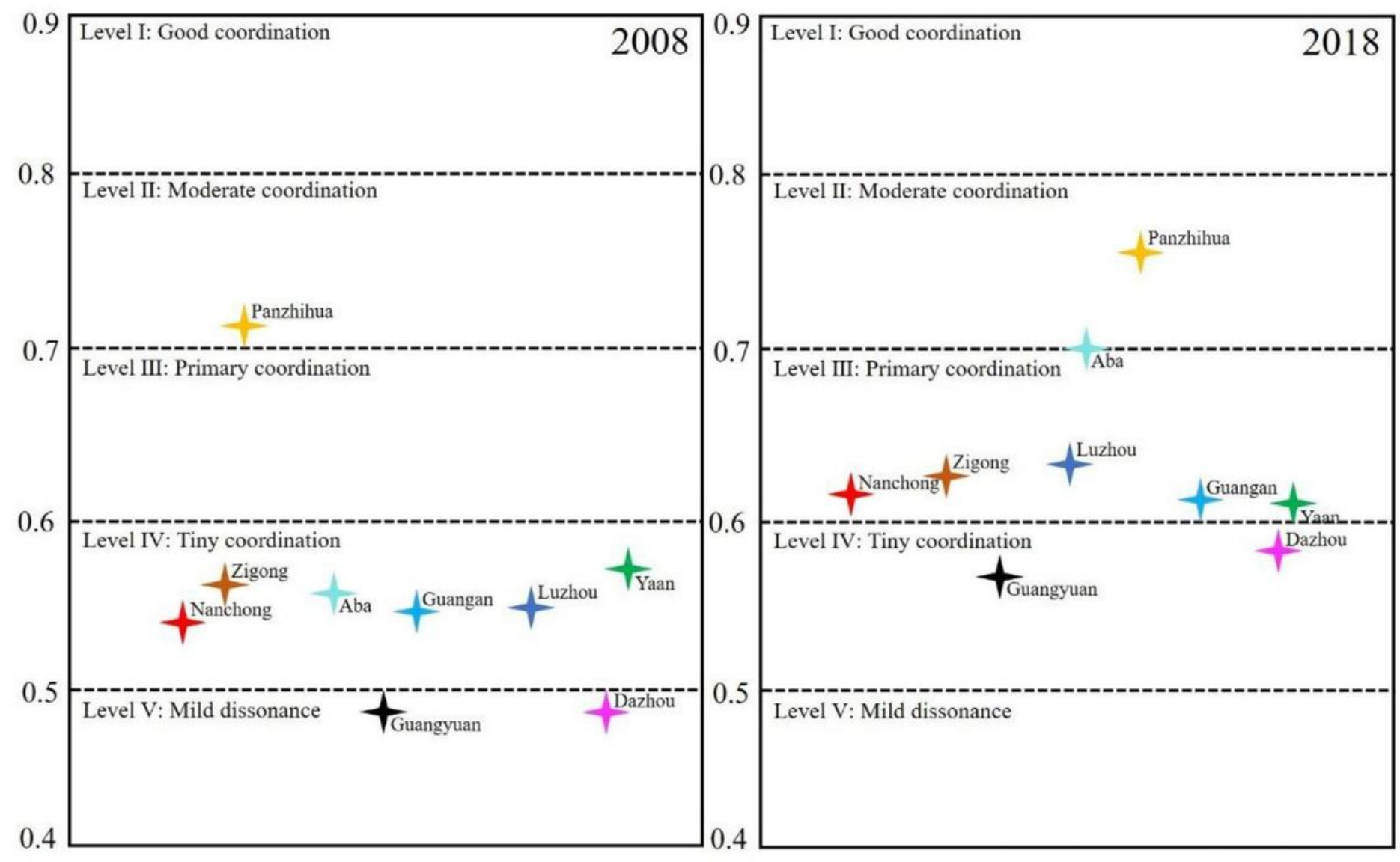


The grade division of the RBCs in 2008 and 2018. 